\title{
Atividade antimicrobiana de extratos peptídicos de folhas de berinjela na inibição do crescimento de Ralstonia solanacearum e Clavibacter michiganensis subsp. michiganensis
}

\author{
Hebréia Oliveira Almeida ${ }^{1}$, Felipe Roberti Teixeira ${ }^{1}$, Reginaldo da Silva Romeiro ${ }^{2}$, Derly José Henriques da Silva ${ }^{3}$, \\ Paulo Roberto Gomes Pereira ${ }^{3}$, Elizabeth Pacheco Batista Fontes ${ }^{1}$, Maria Cristina Baracat-Pereira ${ }^{*}$
}

\author{
${ }^{1}$ Departamento de Bioquímica e Biologia Molecular - BIOAGRO, ${ }^{2}$ Departamento de Fitopatologia, ${ }^{3}$ Departamento de Fitotecnia, Universidade \\ Federal de Viçosa (UFV), 36.570-000, Viçosa-MG, Brasil. \\ *Autor para correspondência. baracat@ufv.br \\ Data de chegada:20/05/2005. Aceito para publicação em:12/02/2007
}

\section{RESUMO}

Almeida, H.O.; Teixeira, F.R.; Romeiro, R.S.; Silva, D.J.H.; Pereira, P.R.G.; Fontes, E.P.B.; Baracat-Pereira, M.C. Atividade antimicrobiana de extratos peptídicos de folhas de berinjela na inibição do crescimento de Ralstonia solanacearum e Clavibacter michiganensis subsp. michiganensis. Summa Phytopathologica, v.34, n.1, p.62-64, 2008

Compostos naturais, incluindo-se peptídios antimicrobianos, vêm se destacando como fontes de agentes de defesa contra fitopatógenos de importância comercial. Esse trabalho visou obter frações peptídicas a partir de extratos de folhas de berinjela e avaliar as atividades antimicrobianas contra duas bactérias fitopatogênicas. Os pools peptídicos catiônicos, PC1 e PC2 e o aniônico PA obtidos de extratos solúvel (ES) e de parede celular
(EP) foram analisados em duas concentrações. Para ES e EP, obteve-se inibição do crescimento da Ralstonia solanacearum e da Clavibacter michiganensis subsp. michiganensis superior a $60 \%$, sendo PC2-2X (maior concentração avaliada) a mais efetiva. Os resultados sugerem que extratos de folhas de berinjela apresentam peptídios com potencial aplicação como agentes de defesa de plantas.

Palavras chave: Peptídio antimicrobiano, solanáceas, defesa de plantas.

\section{Palavras chave: Peptídio antimicrobiano, solanáceas, defesa de plantas.
ABSTRACT}

Almeida, H.O.; Teixeira, F.R.; Romeiro, R.S.; Silva, D.J.H.; Pereira, P.R.G.; Fontes, E.P.B.; Baracat-Pereira, M.C. Antimicrobial activity of peptide extracts of eggplant leaves in the inhibition of Ralstonia solanacearum and Clavibacter michiganensis subsp. michiganensis growth. Summa Phytopathologica, v.34, n.1, p.62-64, 2008

Natural compounds, such as antimicrobial peptides, have been potentially considered as sources of defense agents against commercially relevant phytopathogens. This work aimed to obtain peptide-enriched fractions from eggplant leaf protein extracts in order to evaluate their antimicrobial activities against two phytopathogenic bacteria. The resulting cationic pools, $\mathrm{PC} 1$ and $\mathrm{PC} 2$, and the anionic $\mathrm{PA}$ pool from leaf soluble (ES) and cell wall (EP) extracts were analyzed in two concentrations. For ES and EP, growth inhibition of Ralstonia solanacearum and Clavibacter michiganensis subsp. michiganensis was higher than $60 \%$, being PC2-2X (higher evaluated concentration) fraction the most effective. These results suggest that eggplant leaf extracts contain peptides with potential use as plant defense agents.

Additional keywords: Antimicrobial peptide, solanaceous, plant defense.

Os peptídios antimicrobianos (AMPs) são importantes componentes da defesa inata de plantas e de outros organismos, e sua ação corresponde a uma estratégia de defesa antiga, econômica e com amplo espectro de ação antimicrobiana $(2,5)$. No agronegócio, pesquisas visam obter novos defensivos agrícolas contendo tais compostos (7), já que podem apresentar atividades contra bactérias, fungos, virus e/ ou protozoários e atuam em baixas concentrações com baixa toxicidade e baixo impacto ambiental (2). Os AMPs poderiam contribuir para o controle da murcha e do cancro bacterianos $(3,4)$. O presente trabalho visou avaliar frações peptídicas de extratos solúvel (ES) e de parede celular (EP) de folhas de berinjela quanto à atividade contra fitopatógenos, e identificar princípios ativos para a produção de defensivos agrícolas naturais para uso comercial.

Plantas de berinjela (Solanum melongena, var. Florida Market, Dpto. Fitotecnia, UFV) foram cultivadas em sistema hidropônico e as folhas totalmente expandidas (18 g) foram coletadas e maceradas (1:4, p:v) com Tris-HCl 100 mM pH 7, EDTA, PMSF, benzamidina e tiouréia (9). Após centrifugação, o sobrenadante foi reservado, o precipitado lavado (água, 3 vezes), centrifugado, e os sobrenadantes misturados com o reservado anteriormente, sendo a amostra denominada extrato solúvel bruto (ESB). O precipitado foi ressuspendido em LiCl 1,5 M (1:2,5, p:v), EDTA, PMSF, benzamidina e tiouréia. O homogenato foi agitado, centrifugado e o sobrenadante denominado extrato de parede celular bruto (EPB). As centrifugações foram a $20.300 \mathrm{~g}$ por $30 \mathrm{~min}$ a $4^{\circ} \mathrm{C}$.

ESB e EPB foram separadamente fracionados com sulfato de amônio (35\% sat.), centrifugados, aquecidos $\left(80^{\circ} \mathrm{C}, 15 \mathrm{~min}\right) \mathrm{e}$ centrifugados. Os sobrenadantes ES e EP, respectivamente, foram dialisados (1.000 Da) e cromatografados por troca aniônica (CTA) (DEAE-Sepharose, GE), em equipamento FPLC (BioRad). A coluna (15 mL) foi equilibrada em Tris- $\mathrm{HCl} 25 \mathrm{mM}, \mathrm{pH}$ 7,0, e as amostras fracionadas a 1,0 mL/min, na solução de equilíbrio, na ausência (obter a fração catiônica) e na presença (obter a fração aniônica) de $\mathrm{NaCl} 1$ M. Dois pools catiônicos (PC1 e PC2) e um aniônico (PA) foram obtidos, dialisados e concentrados a $270 \mathrm{~mL}$. Parte de cada pool $(89 \%)$ foi utilizada para testes antimicrobianos em microplacas e parte $(11 \%)$ 
Tabela 1. Atividade antimicrobiana contra Ralstonia solanacearum e Clavibacter michiganensis subsp. michiganensis de extratos (ES e EP) de folhas de berinjela totalmente expandidas, após fracionamento por cromatografia de troca iônica.

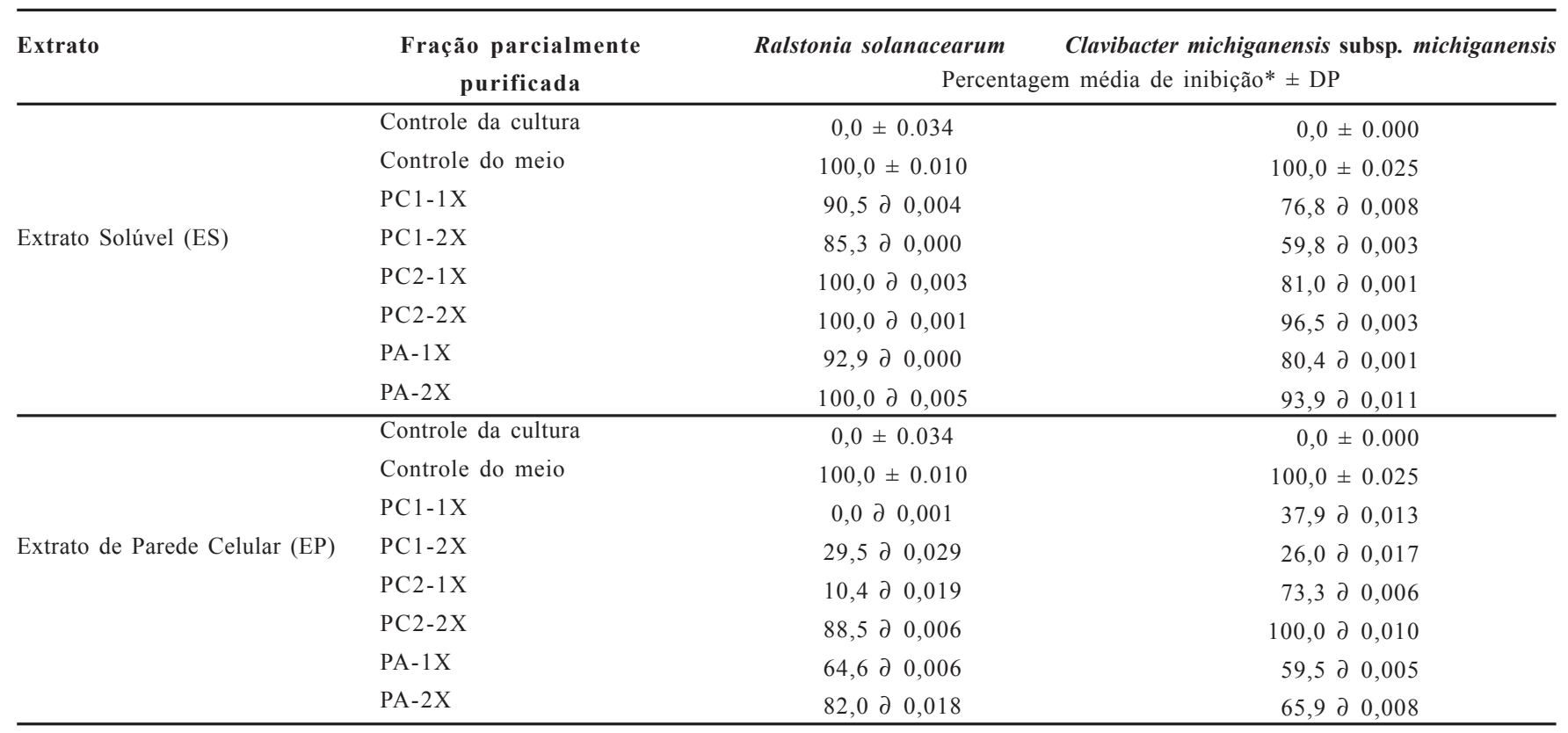

* Os testes foram desenvolvidos em microplacas com capacidade para 96 amostras, avaliando-se os valores de absorvância a 560 nm (A A60 $_{5}$ após 21 $\mathrm{h}$ de cultivo. Para cada ensaio, foram adicionados 50 PL de meio LB concentrado duas vezes $(2 \mathrm{X}), 10 \mathrm{PL}$ da suspensão bacteriana $\left(\mathrm{A}_{560}=1,0-1,2\right)$ e 40 PL da fração peptídica a ser testada (amostras) ou de água ultrapura (controle da cultura). O controle do meio de cultivo consistiu de 50 PL de meio LB 2X e 50 PL de água ultrapura.

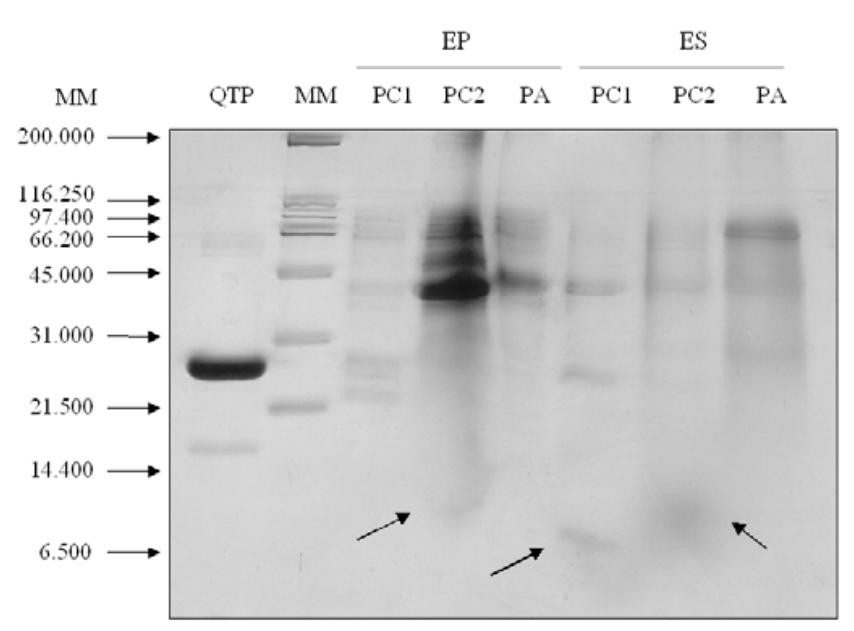

Figura 1. - Eletroforese em gel desnaturante de três fases, em presença de Tricina (SDS-Tricina-PAGE), dos pools catiônicos (PC1 e PC2) e aniônico (PA) dos extratos de parede celular (EP) e solúvel (ES) de folhas de berinjela totalmente expandidas. O gel de três fases (separação, $16,5 \% \mathrm{~T}$ e 3,0\% C, pH 8,9; intermediário, 9,9\% T e 3,0\% C, pH 8,9; concentração, $5,12 \% \mathrm{~T}$ e 2,6\% C, pH 6,8), foi desenvolvido com tampão do catodo contendo Tris-base $0,1 \mathrm{M}$, Tricina $0,1 \mathrm{M}$ e SDS $0,1 \%$ (pH $8,25)$, e do anodo contendo Tris-base 0,2 $\mathrm{M}(\mathrm{pH} 8,9)$. As amostras foram: QTP, $3 \mathrm{Pg}$ de quimotripsinogênio (25.000 Da); MM, padrão de massa molecular de ampla faixa (BioRad), $5 \mu \mathrm{L}$; e PC1, PC2 ou PA de EP ou de ES, 12,5 PL após diálise, liofilização e ressuspensão em 270 PL de água ultrapura. O gel foi revelado com Coomassie Brilliant Blue. As setas indicam a presença de peptídios em PC2 de EP e em PC1 e PC2 de ES. para a separação por SDS-Tricina-PAGE, em mini-gel de três fases (6). As bactérias Ralstonia solanacearum e Clavibacter michiganensis subsp. michiganensis (Depto. Fitopatologia, UFV) foram cultivadas em meio LB líquido, a $28{ }^{\circ} \mathrm{C}$. Os testes foram desenvolvidos em duplicata e em duas concentrações (1X e 2X, 7,4\% e 14,8\%, respectivamente) de PC1, PC2 ou PA.

Frações parcialmente purificadas de ES e EP apresentaram bandas peptídicas (Figura 1) e atividade antimicrobiana (Tabela 1). Nossos resultados mostraram que folhas totalmente expandidas de berinjela possuem peptídios constitutivos com alta atividade antimicrobiana, ao contrário do sugerido por Broekaert et al. (1), que relataram que folhas maduras sadias, em geral, não são boas fontes desses compostos.

PC1-2X, PC1-1X e PA-1X, originadas de ES, inibiram o crescimento de $R$. solanacearum acima de $85 \%$, enquanto que PC21X; PC2-2X e PA-2X promoveram inibição total (Tabela 1). As mesmas amostras promoveram inibições superiores a $60 \%$ para $C$. michiganensis subsp. michiganensis (Tabela 1). A maior inibição foi observada nas maiores concentrações de PC2 e PA, tanto para amostras de ES quanto de EP, indicando que a inibição foi dependente da concentração dos componentes da mistura, característica comum a agentes de defesa comerciais (7). Sugere-se que esses extratos têm potencial para a bioprospecção de agentes de defesa naturais, sendo PC2 a fração mais promissora. Os resultados evidenciaram ainda que PA (de ES ou EP) apresentou atividade antimicrobiana (Tabela 1), porém bandas peptídicas não foram observadas em gel (Figura 1). Peptídios aniônicos podem ser membros da defesa inata de plantas (8).

O perfil eletroforético de PC1, PC2 e PA de ES e EP indicou que a metodologia de enriquecimento dessas moléculas foi satisfatória, e permitiu a visualização de bandas peptídicas (Figura 1). No geral, os AMPs estão presentes em baixas concentrações nos tecidos vegetais 
$(1,2)$. Ainda assim, foi possível observar bandas peptídicas em PC2 de ES e de EP (Figura 1), que são os pools com as maiores atividades antimicrobianas.

Algumas frações inibiram totalmente as culturas das duas bactérias analisadas, uma Gram-positiva e outra Gram-negativa, o que é relevante frente ao objetivo de se encontrar AMPs com amplo espectro de ação antimicrobiana, que atuem como moléculas-modelo para desenvolver produtos de defesa naturais. A alta atividade inibitória observada para $R$. solanacearum é de grande valia pois apenas quatro das dez classes descritas de AMPs de plantas inibem bactérias Gram-negativas (4).

Algumas variedades das solanáceas berinjela, pimentão e pimenta são mais resistentes a Ralstonia solanacearum. A expressão dos AMPs poderia explicar esse fato, por meio de uma defesa pré-existente e constitutiva, ou ainda de uma resposta induzida (2). Como vantagem dessa forma de defesa, observa-se que os AMPs, em função do seu tamanho pequeno, podem ser eficientemente sintetizados de modo rápido e econômico $(1,2)$ e poderiam representar uma nova estratégia na identificação de princípios ativos para o desenvolvimento de novas classes de defensivos para a agroindústria.

\section{AGRADECIMENTOS}

Os autores agradecem às agências FAPEMIG e CNPq.

\section{REFERÊNCIAS BIBLIOGRÁFICAS}

1. Broekaert, W.F.; Terras, F.R.G.; Cammue, B.P.A.; Osborn, R.W. Plant defensins: novel antimicrobial peptides as components of the host defense system. Plant Physiology, Sofia, v.108, n.4, p.1353-1358, 1995

2. García-Olmedo, F.; Rodríguez-Palenzuela, P.; Molina, A.; Alami1lo, J. M.; López-Solanilla, E.; Berrocal-Lobo, M.; Poza-Carrión, C. Antibiotic activities of peptides, hydrogen peroxide and peroxynitrite in plant defense. FEBS Letters, London, v.498, n.2/3, p.219-222, 2001

3. Lopes, C.A.; Santos, J.R.M. Doenças do tomateiro. Brasília: EMBRAPA, CNPH, 1994. 61p.

4. Gerhardson, B. Biological substitutes for pesticides. Trends in Biotechnology, London, v.20, n.8, p. 338-343, 2002.

5. Giacometti, A.; Cirioni, O.; Kamysz, W.; Silvestri, C.; Licci, A.; Riva, A.; Lukasiak, J.; Scalise, G. In vitro activity of amphibian peptides alone and in combination with antimicrobial agents against multidrug-resistant pathogens isolated from surgical wound infection. Peptides, London, v.20, n.11, p.2111-2116, 2005.

6. Judd, R.C. Electrophoresis of peptides. In: Walker, J.M. (Ed.). Methods in molecular biology: basic protein and peptide protocols. Totowa: Humana Press, 1994. chap. 32, p. 49-57.

7. Knight, S.C.; Anthony, V.M.; Brady, A.M.; Greenland, A.J.; Heaney, S.P.; Murray, D.C.; Powell, K.A.; Schulz, M.A.; Worthington, P.A.; Youle, D. Rationale and perspectives on the development of fungicides. Annual Review of Phytopathology, Palo Alto, v. 35, n.1, p.349-372, 1997.

8. Lai, R.; Lui, H.; Lee, W.H.; Zhang, Y. An anionic antimicrobial peptide from toad Bombina maxima. Biochemical and Biophysical Research Communications, New York, v.295, n.4, p.796-799, 2002.

9. Teixeira, F.R.; Lima, M.C.O.P.; Almeida, H.O.; Romeiro, R.S.; Silva, D.J.H.; Pereira, P.R.G.; Fontes, E.P.B.; Baracat-Pereira, M.C. Bioprospection of cationic and anionic antimicrobial peptides from bell pepper leaves for inhibition of Ralstonia solanacearum and Clavibacter michiganensis ssp. michiganensis growth. Journal of Phytopathology, Göttingen, v.154, p.418-421, 2006 